\title{
Seleção de Pessoal — o Estudo do Homem
}

\author{
Tomás de Vilanova Monteiro Lopes
}

\author{
DIFERENÇAS INDIVIDUAIS
}

Q

ONHECIDAS as diferenças ergológicas, isto é, fixados os diferentes tipos de trabalho, há que cogitar das diferenças individuais.

Quando observamos um grupo de individuos podemos notar. logo à primeira vista, como são pronunciadas as diferenças entre êles. Não há dois rigorosamente iguais. Pela compleição, pelos gestos, pelo timbre de voz e por outros traços cada um revela sua individualidade própria e inconfundivel. Aqui encontramos um temperamento calmo, imperturbável, capaz de enfrentar as situações mais dificeis, sem perder a serenidade, a lucidez, o senso de exatidão no pensar e no agir; acolá surpreende-nos a extraordinária capacidade que permite a outro individuo concentrar a atenção, simultâneamente, em várias coisas com um espírito de minúcias que lhes apreende os minimos detalhes; mais adiante deparamos com alguém dotado de excepcional habilidade para lidar com pessoas, captar-lhes a simpatia, desarmar-lhes o ânimo e fazê-las suportarem, pacientemente, as mais incômodas situações. Essas multiformes caracteristicas da personalidade apresentam, ainda, variações de intensidade e grau. As diferenças individuais não são apenas qualitativas, mas, também, quantitativas.

A noção das diferenças individuais é tão antiga quanto a humanidade. O homem primitivo dividia o trabalho, considerando os diferentés graus de fôrça e de destreza de seus semelhantes; e a preocupação de sistematizá-las sob a forma esquemática das classificações dos tipos humanos vem de longe. Já os gregos, partindo de uma engenhosa teoria dos humores-sangue, atrabile, pituita e bile, classificavam os individuos em quatro tipos: o sanguineo, o melancólico, o pituitoso e o bilioso, atribuindo a cada qual uma psicologia própria. De então para cá inúmeras classificações têm surgido. Dentre elas, para dar uma idéia da variedade dos critérios adotados, mencionaremos as de Kretschner, Munsterberg, Fontégne, Mentrè e Thorndike. 
KrEtSChNer, (1) que em suas investigações no campo da psiquiatria fortaleceu a convicção de que as doenças mentais resultam da degenerescência de condições e disposições normais, chegou, através do estudo biográfico de grande número de enfermos, ao estabelecimento de dois tipos característicos da vida psiquica normal: o ciclotímico e o esquizóide. São de tipo ciclotímico as pessoas alegres, sociáveis, brincalhonas, que têm muita facilidade de fazer amigos; e do tipo esquizóide os indivíduos introvertidos, hipersensiveis, de trato difícil e de aparência pouco simpática. Todos êsses traços são muito persistentes e sôbre êles os fatôres exógenos não exercem influência substancial. Raramente, porém, se concentram para dar nascimento a tipos extremos (ciclotímico puro ou esquizóide puro), sendo mais freqüente a sua associação em tipos mistos, embora com predominância desta ou daquela característica.

Os ciclotímicos são, em geral, indicados para certas espécies de trabalho, onde o êxito depende de uma grande adaptabilidade social (comércio, jornalismo, política, etc.), mas em compensação têm tôdas as possibilidades de fracassar nos trabalhos que exijam grande poder de abstração e de isolamento do mundo exterior, trabalhos êstes para os quais os esquizóides são mais bem dotados.

Alfred Binet, (2) analisando o comportamento dos individuos na observação do mundo exterior, caracterizava dois tipos humanos: o objetivo (descritivo e observador) e o subjetivo (contemplativo e sonhador). Ao tipo objetivo atribuía a preocupação de ser exato, de cuidar dos detalhes e de usar uma lingua concreta para transmitir o resultado de suas observações; no tipo subjetivo assinalava a tendência a imaginar, a abstrair, a interpretar, mais do que pròpriamente a descrever, a realidade.

Segundo Munsterberg (3) dois fatôres deveriam, acima de tudo, interessar para a classificação dos tipos humanos; a duração e intensidade das emoções. Dentro dêsse critério foi que êle fixou os quatro tipos seguintes:

1.) temperamentos de emoções lentas, débeis e superficiais; ráveis;

2:) temperamentos de emoções lentas, mas intensas e du-

3:) temperamentos de emoções rápidas, mas débeis e superficiais; $\mathrm{e}$

40) temperamentos de emoções rápidas, mas intensas e persistentes.

(1) Psicologia Médica - Ed. Leyenda - México, 1945.

(2) Idées Modernes Sur Les Enfants - Ed. Flamarion - Paris, 1929.

(3) Psicologia de la Actividad Professional - Madrid, 1914. 
FONTÉGNE (4) propôs uma classificação de base fisiológica, indicando, também, quatro tipos: o digestivo, o muscular, o respiratório e o nervoso. O tipo digestivo é representado pelo indivíduo de abdome pronunciado, grande apetite e fácil digestão, musculatura bem desenvolvida e capacidade para o esfôrço prolongado. Comporta dois subtipos: o gordo e baixo, identificado como "carregador de fardos", e o agigantado, de pernas e braços longos, dotado de movimentos de grande amplitude. O tipo muscular aproxima se do digestivo, mas ostenta maior desenvolvimento da musculatura e menor resistência à fadiga. O tipo respiratório, de altura média ou acima da média, caracteriza-se pelo desenvolvimento do tórax; possui pernas e braços longos, prestando-se a trabalhos que exijam fôrça física e bastante agilidade; é, porém, refratário a ambientes invadidos por gases, odôres intensos e tudo que possa perturbar as boas condições físico-químicas do meio respirável. O tipo nervoso é exemplificado pelo indivíduo magro, ativo, dotado de boa resistência à fadiga e de energia fisica que the permite desenvolver esforços aparentemente desproporcionais à sua compleição.

Mentrè (5) afirmava que a inteligência, através de suas três formas - prătica, meditativa e contemplativa - permitia, melhor do que qualquer outro fator, distinguir os tipos humanos fundamentais, em número de três:

$\left.1^{\circ}\right)$ o que se preocupa com os fins e a utilidade das coisas como os inventores e os homens de negócio (inteligência prática);

2.) o que se preocupa com as relações de base emotiva, como os artistas e os poetas (inteligência contemplativa); e

3) o que se preocupa com as causas e as conseqüências das coisas, como os juristas, os analistas, os geômetras (inteligência meditativa). guia:

THORNDIKE, (6) partindo igualmente da inteligência, distin -

1०) os individuos de inteligência abstrata, aos quais corresponde a aptidão para lidar com símbolos, idéias e palavras;

$\left.2^{\circ}\right)$ os individuos de inteligência concreta, dotados de inclinação natural para lidar com coisas; e

$3^{\circ}$ ) os individuos de inteligência social, com aptidão para lidar com pessoas.

(4) L'Orientation Professionelle et la Determination des Aptitudes Delachaux \& Nestlé S. A., Paris, 1921.

(5) Espèces et Varietées d'Intelligences - Apud Bourdon; L'Intelligence - Felix Alcan, Paris, 1940.

(6) The Measurement of Intelligence - Columbia University - Bureau of Publications - T.C. 
Modernamente, a inteligência, como aptidão geral e fator de diferenciação entre os indivíduos, é encarada menos pela sua natureza do que pelo seu mecanismo, sob uma forma de rendimento, a que se dá o nome de "nivel mental". Neste caso, a classificação dos individuos se processa tomando como ponto de referências um valor que corresponde ao nivel mental médio e é estabelecido, conforme as circunstâncias, a priori ou em função de grupo examinado.

As classificações dos tipos humanos constituem o produto de um esfôrço no sentido de sistematizar os fatôres que produzem as diferenças individuais. Seu caráter de generalidade e simplificação não lhes permite esgotar a matéria nem sequer atender às peculiaridades e minúcias dos casos que se apresentam na prática da seleção de pessoal. Os próprios tipos humanos, ainda que da mesma categoria, diferem entre si por um ou outro aspecto qualquer.

Com o rigor que a divisão do trabalho atingiu nos tempos de hoje, ao problema das diferenças individuais interessa cada vez menos a idéia de profissão (conceito clássico) e cada vez mais a de atribuições (conjunto de tarefas cometidas a alguém). $\mathrm{E}$ à medida que a velha concepção de profissão se vai debilitando, em virtude da modificação dos critérios de organização do trabalho, a de tipo humano (conceito clássico) se vai enfraquecendo também. Desde que já não se trata de selecionar o indivíduo para o campo vasto de uma profissão, mas para o exercício de grupo de tarefas determinadas, a estas se devem restringir as exigências de aptidão e capacidade da pessoa humana.

Ganham, assim, importância, como critério para o estabelecimento das diferenças individuais, as variações de natureza e grau da sensibilidade, imaginação, atenção, memória, reatividade, julgamento, inteligência, resistência à fadiga, etc. Da primitiva noção de "tipo humano" passamos à de aptidão.

FrEeman (7) mostra como essa substituição contribuiu para trazer o estudo das diferenças individuais do terreno meramente subjetivo para o campo da pesquisa estatística, fato que abriu perspectivas novas à seleção de pessoal. E' que quando tomamos um número considerável de indivíduos e os examinamos do ponto-de-vista das variações acima indicadas, os resultados que obtemos podem ser, estatisticamente, reduzidos a um valor médio, em tôrno do qual as diferenças para mais ou para menos se distribuem segundo a curva normal de probabilidade (Curva de Gauss). Isso confere um grau de maior refinamento à determinação das diferenças individuais.

(7) Individual Differences - Henry Halt Ce - New York, 1934. 
$\mathrm{Na}$ prática da seleção de pessoal, os indivíduos costumam. ser examinados:

a) do ponto-de-vista da idoneidade física;

b) do ponto-de-vista das aptidões;

c) do ponto-de-vista do temperamento e do caráter: e

d) do ponto-de-vista dos conhecimentos.

\section{A IDONEIDADE FÍSICA}

O trabalho, pela sua própria natureza ou pelas condições que o cercam, põe em jôgo os nossos diversos aparelhos e sistemas fisiológicos. Certas condições corporais são, por isso mesmo, indispensáveis ao exercício de qualquer atividade profissional. Diz-se que um indivíduo é fisicamente capaz para determinado trabalho, quando possui a constituição orgânica por èste exig̣ida. Incumbência deferida ao serviço médico.

A verificação da idoneidade física para o trabalho abrange, em geral, as seguintes operações:

12) Exame antropométrico: - configuração externa da massa corporal, estatura, pêso, altura, perimetro torácico, tamanho dos membros, dinamometria, indice de rubustez, média de resistência;

2a) Exame dos sentidos hereditários, especialmente tuberculose, cardiapatias, albuminura e afecções nervosas;

3:) Antecedentes pessoais, especialmente reumatismo, doenças infecciosas, escarlatina e doenças da infância, bronquite, pleurisia, especificidade;

4a) Exame dos órgãos: a) Coração: - ritmo: palpitações, intermitências, irregularidades, hipertrofia, lesões vasculares; $b$ ) Aparelho circulatório: epistase, hemofilia, varizes e anemias; c) Aparelho respiratório: bronquite, dispnéia, aderências, tuberculose; d) Figado: icterícia; e) Intestinos: apendicite, hérnia, enterite; f) Aparelho gênito-urinário: hidrocele, ectopia testicular, menstruação, varicocele, incontinência urinária, glicose, albumina; g) Sistema nervoso: paralisias, contrações, tiques e espasmos, tremores, descoordenação, vertigens, emotividade, perturbação da palavra, epilepsia, parkgonismo, coréia; h) Pele e anexos: frieiras e rachaduras, transpiração excessiva das mãos ou dos pés, afecções especificas ou não, adnopatia (de qualquer regiáo); i) Aparelho músculo-articular: atrofia, pseudo-hipertrofia, anquilose, luxações, pé chato, escoliose e defeitos de postura; j) Pescoço: tireóide basedovismo; l) Nariz: adenóides, coriza crônica, epistase; $m$ ) Garganta: hipertrofia das amidalas; $n$ ) Dentição: anomalias.

Os exames médicos determinam, em cada caso, as incompatibilidades e contra-indicações físicas para o trabalho, as quais se acham hoje sistematizadas em inúmeras tabelas, como v.g. a de ClaRK BRIKGES, que reproduzimos a seguir: 


\begin{tabular}{|c|c|c|}
\hline LESÕES & $\begin{array}{l}\text { APTIDÃO DIMINUIDA PARA OS } \\
\text { TRABALHOS QUE IMPORTEM EM: }\end{array}$ & $\begin{array}{l}\text { CONDIÇÕES DE TRABALHO QUE } \\
\text { DEVEM SER EVITADAS }\end{array}$ \\
\hline 1. BRACOS E MĨOS & $\begin{array}{l}\text { Apanhar objetos, fazer pressão, sub- } \\
\text { jugar, manejar, lançar, transpor- } \\
\text { tar, levantar, operar com os dedos, } \\
\text { trepar e balançar. }\end{array}$ & $\begin{array}{l}\text { Calor e umidade que impecam de } \\
\text { usar membros artificiais, mudan- } \\
\text { cas repentinas de temperatura, } \\
\text { frio, umidade no caso de artrites. }\end{array}$ \\
\hline 2. PÉS E PERNAS & $\begin{array}{l}\text { Permanecer de pé, caminhar, saltar, } \\
\text { correr, balançar-se, trepar, arras- } \\
\text { tar-se, inclinar-se, acocorar-se, le- } \\
\text { vantar coisas, transportar, enga- } \\
\text { tinhar. }\end{array}$ & $\begin{array}{l}\text { Mover objetos e veículos, perigo de } \\
\text { resvalar ou tropeçar, lugares de- } \\
\text { masiadamente atravancados, ex- } \\
\text { posição ìs inclemências do tempo. }\end{array}$ \\
\hline $\begin{array}{l}\text { 3. COSTAS E ESPINHA } \\
\text { DORSAL. }\end{array}$ & $\begin{array}{l}\text { Permanecer de pé ou sentado por } \\
\text { longo tempo, andar, correr, saltar, } \\
\text { levantar pesos, transportar, lan- } \\
\text { car e alcançar objetos, contor- } \\
\text { cer-se, inclinar-se, acocorar-se e } \\
\text { engatinhar. }\end{array}$ & $\begin{array}{l}\text { Trabalhos em altura, riscos de des- } \\
\text { lizamentos ou de choques. }\end{array}$ \\
\hline 4. LESŨES DA PELE. & $\begin{array}{l}\text { Exposição a causas conhecidas de } \\
\text { dermatoses industriais; tarefas que } \\
\text { requeiram contato pessoal, no } \\
\text { caso de haver alguma desfigura- } \\
\text { são. }\end{array}$ & $\begin{array}{l}\text { Exposição ao calor excessivo, baixa } \\
\text { umidade, raios ultravioleta, in- } \\
\text { fravermelhos, raios X e bário; } \\
\text { irritantes clássicos da pele (como } \\
\text { alguns solventes e refrigerantes } \\
\text { industriais, etc.). }\end{array}$ \\
\hline 5. TUBERCULOSE & $\begin{array}{l}\text { Atividade física extrema, tensões em } \\
\text { qualquer fase da tarefa; trabalho } \\
\text { excessivo. }\end{array}$ & $\begin{array}{l}\text { Condições que possam causar infec- } \\
\text { sões respiratórias: como umidade, } \\
\text { mudanças de temperatura, corren- } \\
\text { tes de ar, ventilação escassa, pó } \\
\text { de ślica. }\end{array}$ \\
\hline 6. BRONQUTTE & $\begin{array}{l}\text { Atividade física que obrigue a tra- } \\
\text { balho excessivo os sistemas res- } \\
\text { piratório e circulatório. }\end{array}$ & $\begin{array}{l}\text { Irritantes do sistema respiratório } \\
\text { (pó, vapôres, tabaco), mudanças } \\
\text { de temperatura demasiado brus- } \\
\text { cas, umidade extrema, correntes } \\
\text { do ar, pressões atmosféricas anor- } \\
\text { mais, trabalho com líquidos. }\end{array}$ \\
\hline 7.. ASMA CRONICA & As mesmas do número 6 . & $\begin{array}{l}\text { As mesmas do número } 6 \text {. Expo- } \\
\text { são contínua a irritantes espe- } \\
\text { cifieas. }\end{array}$ \\
\hline 8. PLEURISLA & $\begin{array}{l}\text { Atividades que exijam excessivo uso } \\
\text { da respiração, tanto em profun- } \\
\text { didade como em rapidez, ou dos } \\
\text { músculos do peito. }\end{array}$ & As mesmas do número 6 . \\
\hline 9. SINUSITE CRONICA & As mesmas do número 6 . & $\begin{array}{l}\text { Irritantes respiratórios e nasais. Am- } \\
\text { bientes que contribuam para in- } \\
\text { fecções freqüentes das vias respi- } \\
\text { ratórias superiores (ver n. }{ }^{\circ} \text { ). }\end{array}$ \\
\hline 10. SILCOSE & $\begin{array}{l}\text { Atividades que dêem muito traba- } \\
\text { lho ao sistema respiratório (con- } \\
\text { forme sejam as lesóes pulmona- } \\
\text { res). }\end{array}$ & $\begin{array}{l}\text { Pó de súlica e de aberto: ambientes } \\
\text { que encerrem perigo de infeç̧̋̃es } \\
\text { respiratórias (ver n. } 5 \text { ). }\end{array}$ \\
\hline LES & \begin{tabular}{|} 
Variíveis, segundo os casos. Em ge- \\
ral esforgos repentinos, atividade
\end{tabular} & $\begin{array}{c}\text { Condicões ambientais capazes de } \\
\text { produzir infeç̧ões respiratortas }\end{array}$ \\
\hline
\end{tabular}




\begin{tabular}{|c|c|c|}
\hline LESÕES & $\begin{array}{l}\text { APTIDÃO DIMINUIDA PARA OS } \\
\text { TRABALHOS QUE IMPORTEM EM: }\end{array}$ & $\begin{array}{l}\text { CONDIÇÕES DE TRABALHO QUE } \\
\text { DEVEM SER EVITADAS }\end{array}$ \\
\hline & $\begin{array}{l}\text { excessiva; permanecer de pé por } \\
\text { muito tempo, andar, correr, tre- } \\
\text { par, saltar, arrastar-se, transpor- } \\
\text { tar e levantar pesos. }\end{array}$ & $\begin{array}{l}\text { (ver n. } .5 \text { ); riscos de correntes } \\
\text { elétricas; perigos para si mesmo } \\
\text { ou para os demais em caso de } \\
\text { colapso. }\end{array}$ \\
\hline 12. ANEMIA & Atividades físicas excessivas. & $\begin{array}{l}\text { Tóxicos habituais; mudanças repen- } \\
\text { tinas de temperatura; pressões at- } \\
\text { mosféricas anormais. }\end{array}$ \\
\hline 13. VARIZES & Permanecer de pé muito tempo. & $\begin{array}{l}\text { Frio excessivo; riseo de cortes, quei- } \\
\text { maduras ou irritantes da pele, na } \\
\text { parte mais baixa das pernas. }\end{array}$ \\
\hline 14. HÉRNIA & $\begin{array}{l}\text { Levantar objetos pesados ou ativi- } \\
\text { dades que exijam esfôrco dos } \\
\text { músculos abdominais. }\end{array}$ & $\begin{array}{l}\text { Irritantes respiratórios que possam } \\
\text { produzir catarros. }\end{array}$ \\
\hline $\begin{array}{l}\text { 15. ÚLCERA DO ESTOYMA- } \\
\text { GO E DO DUODENO. }\end{array}$ & $\begin{array}{l}\text { Atividades que reclamem esfôrço fi- } \\
\text { sico excessivo. }\end{array}$ & $\begin{array}{l}\text { Pressões atmogféricas anormais pres- } \\
\text { sões repetidas contra as parede- } \\
\text { dos abdome (golpes nas costas } \\
\text { produzidos com } \text { is serras circula- } \\
\text { res); odôres nauseantes. }\end{array}$ \\
\hline $\begin{array}{l}\text { 16. ENFERMIDADES DO } \\
\text { FÍGADO, ICTERÍCIA, } \\
\text { HEPATTTE, CIRROSE. }\end{array}$ & Atividade excessiva. & Tóxicos habituais. \\
\hline 17. SíFILIS & $\begin{array}{l}\text { Não há contra-indicaşoes, a não ser } \\
\text { que também estejam enfermos o } \\
\text { coração e o sistema nervoso, ou } \\
\text { haja perigo de contágio. }\end{array}$ & \\
\hline 18. GONORRÉIA & Não há contra-indicações. & \\
\hline 19. HIDROCELE & $\begin{array}{l}\text { Não há contra-indicaşões, a não ser } \\
\text { em casos extremos. }\end{array}$ & \\
\hline $\begin{array}{l}\text { 20. LESÕES DO RIM; NE- } \\
\text { FRITES, MAL DE BRI- } \\
\text { GHT. LESÕES RENAS. }\end{array}$ & $\begin{array}{l}\text { Atividade excessiva; nos períodos de } \\
\text { nefrite o indivíduo deve manter-se } \\
\text { em repouso. }\end{array}$ & $\begin{array}{l}\text { Exposição aos tóxicos habituais ou } \\
\text { a doengas contagiosas. }\end{array}$ \\
\hline 21. VARICOCELE & $\begin{array}{l}\text { Não hí contra-indicações a não ser } \\
\text { nos casos extremos. }\end{array}$ & \\
\hline 22. DIABETES & $\begin{array}{l}\text { Trepar, correr, saltar, levantar ou } \\
\text { empurrar objetos pesados; ativi- } \\
\text { dade intensa (devido a debilidade } \\
\text { ou lesão do coração). }\end{array}$ & $\begin{array}{l}\text { Trabalhos nes quais as exigêneias } \\
\text { físicas variam de um dia para } \\
\text { outro; exposição a irritantes da } \\
\text { pele; cortes, queimaduras, manu- } \\
\text { seio de ácidos ou metais fundidos; } \\
\text { trabalhos em lugares altos; riseo } \\
\text { de resvalar ou cair; qualquer pe- } \\
\text { rigo de infeccão, tóxicos habituais; } \\
\text { riscos dos olhos. }\end{array}$ \\
\hline
\end{tabular}


Na verificação das contra-indicações físicas para o trabalho, devem ser lembradas estas duas regras:

1ª) a inidoneidade física não é apenas um estado atual, mas também potencial;

$2^{\text {a }) ~ a ~ i n i d o n e i d a d e ~ f i ́ s i c a, ~ l o n g e ~ d e ~ c o n s t i t u i r ~ u m ~ p r o b l e m a ~}$ restrito ao indivíduo, interessa à segurança do grupo do qual êle se destina e que deve ser defendido das doenças transmissiveis, dos acidentes e anormalidades na marcha do trabalho, e dos transtornos resultantes da inutilização dos equipamentos e materiais.

Observe-se, porém, que a capacidade física para o trabalho não é, como se admitia outrora, sinônimo de perfeição física. As experiências realizadas durante e depois das duas últimas guerras, com o objetivo de aumentar as disponibilidades de mão-de-obra e encontrar ocupação condigna para os ex-combatentes mutilados, comprovaram que os defeitos físicos são compensados por certas aptidões, e que mesmo os indivíduos portadores de graves lesões (cegueira, surdez completa, etc.) podem alcançar elevado índice de eficiência em determinadas atividades. O primitivo conceito de capacidade fisica foi pôsto à margem, abandonando-se a idéia de trabalho em geral pela a de trabalho em particular, com o que restring $u$ consideràvelmente a amplitude dos critérios de eliminação.

Hoje em dia, considera-se o individuo fisicamente apto para o trabalho que pode executar, em condições econômicas normais, sem perigo atual ou potencial para si próprio e para outrem.

\section{APTIDÃO, SEU CONCEITO E ASPECTOS FUNDAMENTAIS}

A aptidão, conforme a melhor doutrina, é uma disposição natural do individuo para determinada atividade ou, como disseram Sollier e Drabs (8) uma disposição natural para fazer alguma coisa, sem educação prévia, melhor e mais fàcilmente que a média dos indivíduos nas mesmas condições. Sendo uma disposição natural, existe independentemente da aprendizagem e do treinamento, o que vale dizer é inata e não adquirida. Contudo, tal qual os demais aspectos da personalidade humana, pode ser desenvolvida e aperfeiçoada pelo treinamento; quando isso acontece surge, então, a capacidade. Esta é, a rigor, uma questão de melhoria do exercicio da aptidão: quanto maior a capacidade do individuo, tanto mais aperfeiçoada a sua técnica de usar a aptidão que possui.

Aptidão e capacidade cabem num conceito mais amplo: o de idoneidade. "A aptidão - observa FIngerman (9) - é o

(8) Op. Cit. 1954.

(9) Fundamentos de Psicotécnica - Liv. El Ateneo - Buenos Aires, 
aspecto subjetivo da idoneidade, enquanto que a capacidade é seu aspecto objetivo, porém, em última instância, não poderia haver capacidade para algo, se não existisse uma aptidão natural subjacente".

Costuma-se dizer que a aptidão encerra dois aspectos essenciäis: a facilidade de aprendizagem e a satisfação pessoal. Mas há, sem dúvida, um terceiro aspecto, para o qual CLApARr̀dE (10) chàma a atenção: o rendimento.

Ao indivíduo apto para determinada atividade esta se apresenta como de fácil aprendizagem. A facilidade gera o interêsse; mas êste, por sua vez, atua no sentido de favorecer a aprendizagem, assumindo, assim, a dupla feição de causa e efeito. O individuo interessa-se pela atividade porque lhe é fácil aprendê-la; e a considera fácil porque por ela se interessa. Os dois fatôres: facilidade de aprendizagem e interêsse - conduzem a dois outros: a satisfação pessoal e o alto rendimento. $O$ exercicio da aptidão desenvolve um certo «élan afetivo» que permite ao indivíduo libertar-se da sensação de esfôrço e de pena, para encontrar no trabalho uma forma de satisfação e de bem-estar. O rendimento quantitativo e qualitativo que o trabalhador consegue obter, sob tais condições, é maior que o de média dos individuos não sujeitos a uma tal motivação. CLAPARÈDE afirmou que aptidão é todo caráter psíquico ou físico, considerado sob o ângulo do rendimento, e que êste, implicita ou explicitamente, se refere a uma norma. A aptidão é tanto mais elevada, quanto mais o rendimento ultrapassa a norma.

Porque predispõe o individuo a ser proficiente no trabalho a apt:dão é geralmente considerada uma qualidade positiva, uma virtude, um predicado, um dom. Esse modo de encará-la só é inteiramente verdadeiro, do ponto-de-vista do trabalho respectivo. Face à moral e à própria fisiologia humana, a aptidão pode ser uma qualidade negativa, um defeito. A dissimulação maliciosa nãc é, positivamente, uma virtude, mas nem por isso deixa de ser uma aptidão para certas atividades, como as de espionagem e polícia por exemplo. O daltonismo, que é um defeito físico, foi utilizado durante as duas últimas guerras como aptidão para trabalhos de reconhecimento e localização de objetivos militares camuflados.

Mas há ainda uma outra lição a tirar daí: a aptidão para determinado trabalho pode consistir em contra-indicação para outros. Quem ignora que o daltonismo é uma contra-indicação para os trabalhos de motorista, ou que a dissimulação maliciosa é uma qualidade negativa para os trabalhos de pesquisa e de análise cientifica?

(10) Como Diagnosticar as Aptidões nos Escolares - trad. de Leal Júnior - Porto, 1931. 
Uma das características da aptidão é a sua constância. Através das flutuações da emotividade que explicam as nossas variações de conduta e nos dão a impressão de inconstância da personalidade humana, as aptidões conservam uma estabilidade essencial. Alguém que possua aptidão para a caricatura, para música ou para outra coisa qualquer, continuará a tê-la nos estados de exaltação ou de depressão, nos momentos de alegria cu tristeza, de cólera ou serenidade. Os estados emotivos profundos, é certo, podem afetar o exercício das aptidões, mas não lhes prejudicam a estrutura. As alterações e a perda, total ou parcial, da aptidão, resulttam de acidentes ou de enfermidades.

A constância das aptidões é um característico importante, uma vez que sem ela os prognósticos formulados pela seleção de pessoal teriam valor muito precário.

Qualquer que seja a sua natureza a aptidão, ao invés de manifestar-se desde logo completa, obedece a uma evolução, na qual se distinguem três fases: a progressiva, a estática e a regressiva. Na fase progressiva ela se manifesta e desenvolve num ritmo que depende de fatôres inerentes ao próprio individuo e de condições do meio externo, até atingir o amadurecimento. Daí em diante se mantém por período relativamente longo no mesmo nivel (fase estática) e, afinal, entre em declinio (fase negativa).

Podem as aptidões, conforme sua natureza, ser agrupadas em categorias distintas. ClLAPARÈDE (11) propõe seu agrupamento em quatro categorias:

$\left.1^{a}\right)$ aptidões sensoriais (disposições para discriminar côres, perceber formas, distinguir ruidos, odôres, graus de temperatura, etc.); tos);

$2^{3}$ ) aptidões motoras (disposições para realizar movimen-

$3^{\text {a) }}$ aptidões intelectuais (disposições de caráter psicológico, tais como a atenção, a memória, a inteligência, etc.);

$4^{4}$ ) aptidões afetivas (disposições para sentir o belo, o feio, o agradável, o desagradável, etc.).

As aptidões além de se distinguirem pela sua natureza, apresentam, ademais, diferentes graus de complexidade. Algumas podem ser decompostas em elementos simples, outras não. Aquelas se dizem complexas e estas, elementares.

Cada individuo tem várias aptidões, o que suscita a questão de saber se estas são ou não independentes umas das outras. Embora muitos autores sustentem que as aptidões não se influenciam recìprocamente, sempre se impôs a idéia de que elas estão ligadas por um elemento comum. Tal elemento, inicialmente referido por Flourens, como uma "capacidade geral", foi mais

(11) Op. Cit. 
tarde identificado por Spearman, cuja teoria dos dois fatôres alcançou grande notoriedade. Segundo SpEArman tôda aptidão resulta do concurso de dois fatôres, um dos quais (fator G) é comum e geral, enquanto que o outro (fator S) é especifico. Deve-se ao fator especifico o fato de uma aptidão possuir sua fisionomia própria e distinguir-se das demais que com ela integram o mesmo conjunto. Na teoria de Spearman teve origem a teoria multifatorial que sustenta a existência de vários fatôres gerais ao invés de um só, mantida, porém, a idéia inicial de que as aptidões de um indivíduo são ligadas entre si por algo comum que as unifica e lhes imprime a feição de conjunto e diversificadas por algo específico que as orienta no sentido de uma atividade particular.

Spearman concebeu sua teoria ao observar a tendência para uma variação, dentro de proporções determinadas, dos coeficientes de correlação obtidos com a aplicação de uma bateria de testes. A aludida tendência, que recebeu a denominação de ordem hierárquica, resulta, segundo SpEARMAN, do fato de serem tôdas as correlações devidas a um fator único, presente em cada teste, porém em mais alto grau nuns do que noutros. Tal fator é precisamente o fator $\mathrm{G}$.

Uma ordem hierárquica perfeita é muito difícil de verificar -se na prática. O problema, como ponderam THomson E Brown, (12) consiste, pois, em saber qual a margem de tolerância que se pode admitir, sem abandonar a idéia de fator geral.

As teorias fatoriais da aptidão têm despertado grande interêsse, sobretudo entre os psicólogos inglêses e americanos, mas a verificação objetiva do seu valor ainda permanece no terreno da dúvida. Mordecai Ezequiel (13) adverte que os resultados das investigações realizadas, não obstante envolverem cálculos complexos e altas elaborações matemáticas, têm uma significação ainda não muito firme. Não se lhes contesta, contudo, o valor metodológico, face às possibilidades que oferecem no sentido de uma futura substituição dos processos puramente verbais e descritivos pela análise matemática das aptidões.

\section{APTIDÃO, INTELIGÊNCIA E PROFISSÃO}

Quanto mais se foram aprofundando os estudos a respeito das aptidões, mais evidente se foi tornando o importante papel que nelas desempenha a inteligência. Esta, que em si mesma é uma aptidão, está intimamente associada às demais aptidões que

(12) The Essentials of Mental Measurements - Cambridge Uriversity Press, 1940. 1941.

13) Methods of Correlation Analysis - John Willey \& Sons, New York, 
num certo sentido dela dependam. Como estados virtuais e fôrças latentes as aptidões se revelam pelo exercicio e se aperfeiçoam pelo treinamento. Exercício e treinamento pressupõem aprendizagem e, portanto, inteligência.

Muitos autores acreditam mesmo que o fator $\mathrm{G}$ a que aludia Spearman outra coisa não é senão a inteligência geral (general ability), cujo conceito, como veremos a seguir, comporta larga margem de controvérsia.

Pelo menos de quatro pontos-de-vista diferentes: - o biológico, o educacional, o clássico e o empírico - podemos conceber a inteligência. (14)

O ponto-de-vista biológico é bem representado por STERN que definiu a inteligência como uma capacidade geral que permite ao indivíduo ajustar seu pensamento às situações novas. De acôrdo com essa concepção, a inteligência é tanto mais elevada quanto maiores forem a facilidade, a riqueza de recursos e a proficiência com que nos libertamos de velhos hábitos e adquirimos outros novos. Os partidários do ponto-de-vista educacional, salientando-se entre êles HEMON e Colvin. concebem a inteligência como capacidade de aprender. Os critérios para sua medida seriam, assim, a quantidade e a qualidade do conhecimento adquirido. Segundo o ponto-de-vista clássico, do qual Burt, Terman e HAGGERTY são os partidários mais destacados, por inteligência se deve entender um "conceito prático que designa um grupo de fenômenos mentais complexos, tradicionalmente definidos nas psicologias sistemáticas, como sensação, percepção, associação, memória, imaginação, juizo e raciocínio. Finalmente, o ponto-de-vista empírico, ao qual aderiram Thorndike, Ballard, Pik̀ron e os "behavioristas" em geral, vê a inteligência como o poder de boas respostas, do ponto-de-vista da verdade ou do fato. $\mathrm{Na}$ sintese expressiva de PIÈron, a inteligência não é senão um «comportamento-valor".

Cada uma dessas definições da inteligência é passivel de crítica. Poderiamos objetar, contra a primeira delas, que, no terreno prático é muito dificil encontrar correspondentes exatos para expressões tais como "novidade de um problema" ou "situações novas". Ademais, a definição de STERN fala em capacidade de àlaptação, e esta envolve, ao lado de fatôres intelectuais, fatôres emocionais. Além disso, em face dos problemas da vida, nem sempre o individuo inteligente assume uma atitude de acomodação; muitás vêzes, ao invés de adaptar-se, insubordina-se, entra em conflito com as idéias do tempo e do meio em que vive. Os grandes artifices do progresso humano foram, de algum modo, indivíduos desajustados, inadaptáveis, e se não o fôssem não teriam aberto novos caminhos à humanidade. Por outro lado,

(14) Veja-se: Intelligence Tlests Methods and Results - Rudolph Pintner. Henry Holt C', New Yo:k, 1939. 
definir a inteligência como capacidade de aprender é não só incidir em dubiedade (capacidade de aprender coisas mais dificeis? ou capacidade de aprender ràpidamente?), como também omitir o lado finalistico do conhecimento, que não pode ser desprezado na caracterização da conduta do homem inteligente. As definições empiricas, ainda que pareçam rìgidamente objetivas, não se podem dizer menos vulneráveis, uma vez que a "verdade" ou - "fato" em que elas assentam a apreciação do comportamento, como valores pragmáticos, são sobretudo contingentes.

A verdadeira noção de inteligência, conforme diz BourDON, (15) é aquela a que chegamos quando empreendemos o estudo dos fenômenos intelectuais, partindo dos outros fenômenos primitivos que os antecedem e dos quais êles dependem. Um estudo dessa ordem nos levará a reconhecer, afinal:

19) que ao invés de uma inteligência solúvel, o que devemos considerar é o resultado de um comportamento complexo, no qual tôda a vida mental intervém (Pİ̀ron);

2.) que a inteligência se manifesta sob diversas formas: o homem inteligente não só aprende bem e ràpidamente, como também se adapta às situações novas da vida, pensa reflexivamente, expressa suas idéias com clareza e exatidão, está com o espirito sempre alerta (Aguayo).

Para Thorndike (16) a inteligência possui quatro atributos:

- nivel (grau de dificuldade dos problemas que o individuo é capaz de responder):

- extensão (número de problemas que, num determinado grau de dificuldade, o indivíduo pode solucionar);

- área (resultado da soma das extensões dos diversos niveis); e

- rapidez (que se avalia em função do tempo dispendido na solução dos problemas).

A êsses atributos, STodDard (17) acrescenta quatro outros: a abstração, que permite a atividade simbólica e conceitual; a adaptação a um fim, que exprime a relação de conveniência entre o ato inteligente e a situação à qual com êle procuramos nos adaptar; a originalidade que caracteriza 0 ato inteligente como uma forma de comportamento nova, oposta ao hábito e à rotina, e o valor social.

A existência de provas capazes de medir a inteligência com a necessária precisâo, possibilitava, mediante a aplicação de tais

(15) L'Intelligence - Liv. Felix Alcan. - Paris, 140.

(16) Op. Cit.

(17) The Meaning of Intelligence - The Mac Millan C?. New York, 1943. 
provas a grandes massas de indivíduos pertencentes às diversas categorias profissionais, o estabelecimento do grau de inteligência correspondente a cada profissão. Esse trabalho foi realizado pela Comissão de Exame Psicológico de Recrutas do exército norteamericano, em 1917, aproveitando-se, para isso, a oportunidade de pesquisa em larga escala proporcionada pela primeira guerra mundial, com a mobilização de vastos contingentes de conscritos, cuja distribuição pelas inúmeras tarefas profissionais próprias de um exército moderno deveria obedecer a critérios rápidos e seguros. Com a aplicação dos "Army Mental Tests", formas Alpha e Beta, a Comissão de Exame Psicológico de Recrutas estabeleceu os sete seguintes graus de inteligência:
A ) - muito superior (nota no teste: 135 a 212 pontos)
B ) - superior (idem: 105 a 135 pontos)
$\mathrm{C}^{+}$) - média elevada (idem: 75 a 104 pontos)
C ) - média (idem: 45 a 74 pontos)
C-) - média baixa (idem: 25 a 44 pontos)
D ) - inferior (idem: 15 a 24 pontos)
D-) - muito inferior (idem: 0 a 14 pontos)

Os indivíduos dos grupos A e B foram considerados intelectualmente aptos para as funções de oficiais; os do grupo $\mathrm{C}+$ e, eventualmente, os do grupo C, para o suboficialato; os do grupo $\mathrm{C}$-, como possuidores da inteligência necessária a um bom soldado; os do grupo D, como dotados da inteligência caracteristica do soldado simplório, cujo treinamento exige tempo e paciência; e finalmente os do grupo D-, como capazes, apenas, para a execução de serviços braçais.

A seguir, várias organizações de ensino e emprêsas privadas desenvolveram êsse trabalho pioneiro que se tem revelado de grande utilidade para a pedagogia e a administração de pessoal.

A medida que os progressos da tecnologia vão tornando cada vez. menos necessária a fôrça bruta e mais indispensável a atividade intelectual do trabalhador, a inteligência como elemento de diferenciação entre os indivíduos adquire maior interêsse para a seleção de pessoal.

$E^{\prime}$ fato experimentalmente comprovado que os melhores trabalhadores são, em geral, os individuos mais inteligentes do seu grupo. Isso deve ser entendido, porém, dentro de uma certa correspondência entre o grau de inteligência e a natureza do trabalho a executar. Um indivíduo de inteligência superior não se sentirá bem executando tarefas demasiadamente fáceis. Com a mesma rapidez com que consegue aprendê-las, por elas se desinteressa, a ponto de julgá-las insuportáveis. A inteligência muito superior ao nivel que o trabalho requer constitui uma das mais freqüentes causas de desajustamento profissional. De outro 
lado, a inteligência abaixo daquele nivel caracteriza o trabalhador retardado, cujo adestramento é difícil e pouco produtivo.

Quem lida com o problema de distribuição do trabalho deve, pois, ter a constante preocupação de procurar para cada tipo de atividade o trabalhador que possua o nivel de inteligência correspondente.

As aptidões, como qualidades pontenciais e latentes, não são suscetiveis de medida direta. Apenas podemos medi-las, indiretamente, através do rendimento alcançado pelo individuo nas situações reais de trabalho (exercicio da profissão) ou nas situações provocadas experimentalmente (provas de aptidão). A princípio empregava-se, exclusivamente, o primeiro processo: 0 individuo era admitido ao trabalho, a titulo precário, e, se se revelasse incapaz de exercê-lo a contento, dispensado. A dispensa do empregado admitido nessas condições fazia-se quase sempre preceder de acidentes, danos do equipamento de trabalho, desperdicio de nıatérias primas, além do tempo perdido pelo empregador, cujos programas ficavam à espera de que a sorte lhes proporcionasse o trabalhador com as caracteristicas desejadas. Tais inconvenientes tornavam-se cada vez mais onerosos, à medida que as leis de proteção ao trabalho iam limitando o arbitrio dos empregadores na admissão e dispensa dos empregados. Cogitou-se, então, de descobrir um meio que assegurasse o diagnóstico das aptidões dos individuos, antes de sua admissão ao emprêgo. Êsse meio, o teste, não tardou a ser pôsto a serviço da seleção de pessoal.

O teste, como bem o definiram Sollier e Drabs, (18) é uma prova rápida, destinada a:

1\%) Pôr em evidência uma qualidade funcional qualquer, isolada quanto possivel, no complexo da atividade psicofisiológica geral; e

2.) Graduar essa qualidade por diferenciação entre numerosos indivíduos e por variação num mesmo indivíduo.

Há, hoje, uma grande variedade de testes, para aplicação individual ou coletiva, uns exigindo o uso de aparelhagem ou de dispositivos especiais, outros exigindo, apenas, o emprêgo de lápis e papel. A bibliografia nacional a respeito do assunto já é bastante extensa e a ela poderá recorrer o leitor interessado em maiores informações.

Em cada caso, a escolha dos testes a serem adotados deverá ser feita, levando-se em conta os resultados da análise do trabalho; é tarefa que requer conhecimentos e tirocínio em psicologia aplicada.

(18) Op. Cit. 
Um bom teste deve ser válido (adequado àquilo que se deseja medir), constante na medida, seletivo (capaz de distinguir as variações de rendimentos), simples, econômico e de fácil uso. Tais requisitos costumam ser apurados, mediante um ensaio prévio que consiste na aplicação do teste a um grupo de contrôle. Mais adiante, quando expusermos a técnica geral de organização da prova objetiva, as noções aqui expostas serão ampliadas.

\section{O TEMPERAMENTO E O CARÁTER}

O temperamento e o caráter são de extrema importância para o êxito ou fracasso do indivíduo em qualquer profissão, muito especialmente nas de nível superior. As aptidões pouco valem, quando desacompanhadas da fôrça de vontade, do sentimento de autoconfiança, do espírito de decisão, da energia, da coragem, da honestidade, da ambição, da paciência e de outros traços do caráter.

Temperamento e caráter são coisas distintas, mas de tal forma interligadas que freqüentemente se confundem na compreensão de quem as estuda. Conforme a melhor doutrina, temperamento é um fator físico constitucional que resulta da predominância de um órgão ou de um sistema e determina a maneira pela qual o indivíduo tende a reagir aos estímulos 'do meio ambiente; caráter é um fator psicológico que se constitui da totalidade das reações psíquicas do individuo, ou, como diria Baumgarten, (19) traduz a maneira pela qual o individuo assegura a conservação e o desenvolvimento de sua personalidade. Para tornar mais acessivel essa distinção costuma-se dizer que o temperamento é a face fisiológica da personalidade; e o caráter sua face psicológica.

A verificação do caráter é um dos mais difíceis problemas da seleção de pessoal. BAumgarten aponta como responsáveis por essa dificuldade:

1\%) a maneira equivoca sob a qual se manifesta o comportamento caracterológico (atitudes aparentemente iguais podem ser inspiradas por motivos diametralmente opostos);

2.) a relatividade dos traços de caráter (as diferentes situações da vida condicionam a maneira de ser do individuo);

3) a correlação das qualidades morais (raramente tais qualidades guardam harmonia entre si; a alma humana é cheia de contrastes);

(19) Orientation et Selection Professionnelles par l'Examen Psychologique du Caractére - Dunod, Paris, 1954. 
4\%) a variabilidade do caráter (a moléstia, os acidentes, os grandes choques emocionais podem transformar inteiramente a fisionomia psíquica e moral do individuos);

5?) o perigo dos prognósticos ilusórios (o fato de se cons tatar a presença de certo traço de caráter numa pessoa não autoriza afirmar que por êle se regerá a conduta dessa pessoa);

6:) a significação profissional dos traços de caráter negativos (a ausência de algumas qualidades positivas pode não ter importância do ponto-de-vista do êxito profissional, do mesmo passo que a posse de certos defeitos pode ser essencial a êsse êxito);

79) a impressão de afronta que o prognóstico desfavorável costuma produzir (o individuto não se agasta de se lhe dizer que possui "memória fraca"; mas se se lhe forem atribuidos ciefeitos de caráter sentir-se-á ofendido).

No afã de vencer as dificuldades que cercam a verificação do caráter, por processos rápidos e fidedignos, os psicólogos têm imaginado vários tipos de provas, como os "inventários" os "testes projetivos". Tais provas, a nosso ver, apresentam a desvantagem de não conseguirem reproduzir, de modo real e atuante. o conjunto das circunstâncias (situações de perigo, de tentação, de desgraça, de competição, de segurança, etc.), através das quais o caráter se revela no curso da vida profissional. Por outro lado, a relatividade e a variabilidade próprias do caráter concorrem para diminuir o valor do prognóstico obtido mediante provas de curta duração, sobretudo quando, como acontece na maioria dos casos, êsses resultados sofrem ainda a influência do trabalho de interpretação a cargo do examinador. Os inventários e os testes projetivos estão, por isso, muito longe de satisfazer as necessidades da seleção de pessoal; no campo da psiquiatria, porém, seus méritos têm sido comprovados.

A verificação do caráter da seleção, como parte do processo de seleção se faz, via de regra por meios ecléticos, aliando-se às provas psicológicas, a sondagem da vida pregressa do indivíduo, e a observação da sua conduta no trabalho, durante a fase do estágio probatório.

\section{OS CONHECIMENTOS}

O trabalho é, em última análise, aplicação de conhecimentos, visando à determinada utilidade. Para exercê-lo convenientemiente, o indivíduo precisa saber umas tantas coisas. A reunião das aptidões e dos conhecimentos exigidos pelo trabalho (conhecimentos especificos) produz a "capacidade atual"; a simples posse das aptidões e de certa soma de instrução (conhecimentos 
gerais) produz a "capacidade potencial". A capacidade atual habilita o indivíduo a exercer o trabalho desde logo; a capaci dade potencial o qualifica para adquirir, através da aprendizagem, os conhecimentos especificos de que necessita para o exercicio eficiente do trabalho.

Via de regra os individuos são selecionados pela sua capacidade atual (sistema norte-americano); a seleção pela capacidade potencial (sistema inglês) costuma ser empregada quando os meios de formação de pessoal não atendem, nas condições desejadas, as necessidades dos empregadores. Em qualquer dos casos a apuração dos conhecimentos tem grande importância. Quando se pratica a seleção pela capacidade potencial, os conhecimentos gerais, o nível de instrução, é que são levados em conta; quando se pratica a seleção pela capacidade atual, são os conhecimentos específicos que interessam. 